\title{
O uso do xadrez enquanto realização lúdica que favorece a aprendizagem e ensino de geografia na educação básica
}

\author{
The use of chess while playing that favors geography learning and \\ teaching in basic education
}

\section{Émerson Dias de Oliveira' ${ }^{\circledR}$, Cleiton Costa Denez"I ${ }^{\circledR}$, Josiane Mendes Peschisky"III)}

\begin{abstract}
' Universidade Estadual de Londrina - UEL, Laboratório de Geografia, Território, Meio Ambiente e Conflito (GEOTMAC). Pedagogo da Secretaria Municipal de Educação, Cultura e Turismo - SEMECT, Laranjeiras do Sul, PR, Brasil.

" Universidade Estadual de Maringá - UEM. Grupo de Pesquisa Redes de Poder, Migrações e Dinâmicas Territoriais (GEPES/UNICENTRO). Professor da Secretaria de Estado de Educação do Paraná - SEED/PR, Curitiba, PR, Brasil.

III Universidade Estadual do Centro-Oeste - UNICENTRO. Professora da Secretaria Municipal de Educação, Cultura e Turismo - SEMECT, Laranjeiras do Sul, PR, Brasil.
\end{abstract}

\section{RESUMO}

O presente estudo percebe o jogo de xadrez enquanto uma ferramenta pedagógica de importância crucial para o desenvolvimento integral das crianças, sendo que aqui foram apontadas algumas das várias contribuições que essa iniciativa exerce no meio educacional. As discussões estão voltadas em apresentar a aplicabilidade desse jogo no ensino de geografia, um esforço que teve como desafio se utilizar dos vários simbolismos presentes em uma partida de xadrez para inserir com maior efetividade e concretude os principais conceitos geográficos. O desenvolvimento do trabalho utilizou-se do aporte bibliográfico enquanto base metodológica, sendo resgatados autores da área específica de xadrez, do ensino e de algumas categorias fundantes da disciplina geográfica. Foram colocados também os benefícios pedagógicos que xadrez possibilita aos jogadores envolvidos, sendo que para tanto a pesquisa fez uso de um significativo resgate bibliográfico de autores que refletem essa temática na esfera escolar. Enfim, sem o propósito de reduzir essa iniciativa ao jogo em si, as provocações aqui instruídas buscam incutir o sentido de que todos os envolvidos nesse jogo de tabuleiro são beneficiados, incluindo a platéia, o professor, o vencedor e até mesmo o perdedor. Esse último se conscientiza do esforço empregado no jogo, impregnado de decisões equivocadas e acertadas. Assim, cabe ao professor utilizar desse ambiente para fazer analogias com o intuito de construir e consolidar aprendizagens significativas em sala de aula.

Palavras-chave: Ensino; conceitos geográficos; desenvolvimento cognitivo; jogo lúdico 


\section{ABSTRACT}

The present study perceives the chess game as a pedagogical tool of crucial importance for the integral development of children, and here some of the various contributions that this initiative exerts in the educational environment were pointed out. The discussions are aimed at presenting the applicability of this game in the teaching of geography, an effort that had the challenge of using the various symbolisms present in a chess game to more effectively and concretely insert the main geographical concepts. The development of the work used the bibliographic contribution as a methodological basis, being rescued authors from the specific area of chess, teaching and some founding categories of the geographical discipline. The pedagogical benefits that chess provides to the players involved were also mentioned, and for both the research made use of a significant bibliographic review of authors who reflect this theme in the school sphere. Finally, without the purpose of reducing this initiative to the game itself, the provocations instructed here seek to instill the sense that everyone involved in this board game is benefited, including the audience, the teacher, the winner and even the loser. The latter becomes aware of the effort used in the game, impregnated with wrong and correct decisions. Thus, it is up to the teacher to use this environment to make analogies in order to build and consolidate meaningful learning in the classroom.

Keywords: Teaching; geographic concepts; cognitive development; playful game

\section{INTRODUÇÃO}

As inquietações e ansiedades presentes no cotidiano da geração Millenium (Z), usuários da educação contemporânea, compreendem um cenário desafiador para que se efetue uma aprendizagem significativa, a qual seja produtiva nas diversas perspectivas e possibilidades de análises sociais. É por isso que a formação de sujeitos críticos e dotados de uma visão holística do mundo, exige cada vez mais uma estruturação didático-pedagógica que dê conta de demandas/desejos imediatistas, instantâneos e de elevada fluidez que caracterizam esse cenário da "modernidade líquida" (BAUMAN, 2007). Essa geração da conectividade virtual e das redes sociais é paradoxalmente pulverizada de medos, hesitações e solidão, sendo que o refúgio e suporte de tais sensações são (pseudo) encontrados na internet com suas inúmeras plataformas/mídias, onde forjam seus abrigos/relações virtualizados.

Diante disso, é inegável reconhecer que a escola de hoje não é e nem poderia perpetuar as pedagogias realizadas há alguns anos. Afinal, os discursos, valores e práticas da "Sociedade da Informação" (CASTELLS, 2000) exigem atualizações 
recorrentes por parte de seus indivíduos, parâmetro esse que atinge de forma ainda mais direta e objetiva os profissionais da educação. Portanto, interpretar o diálogo 'gameficado' dos jovens e com isso construir analogias e links com os compostos teóricos são capacidades peculiares para conseguir dar significado às aulas, isto é, trata-se de uma necessidade que se apresenta como recurso que alinha e aproxima as trocas do-discentes. Afinal, "brincando e jogando, o jovem terá a oportunidade de desenvolver capacidades indispensáveis na sua futura atuação profissional, tais como: atenção, afetividade, concentração, tomada de decisões e outras habilidades psicomotoras" (BERGAMO, 2010, p. 05). Dito isso, é notório que a didática mnemônica, descritiva e desinteressante a práxis originária desses alunos deve ceder lugar para intervenções pedagógicas interessantes, instigantes e produtivas.

É importante frisar que tais formatações educacionais carecem de serem instruídas enquanto meio e não como fim no processo de ensino-aprendizagem, uma vez que a aquisição de conhecimentos teóricos (bem como as questões gerais de sociabilidade) atrelados em cada faixa etária correspondente continua sendo o propósito central imbuídos na função social da escola. Sabendo desse cuidado e critério quanto aos desígnios da escola, o presente estudo se reveste em apresentar a aplicabilidade desse jogo no ensino de geografia, trazendo à tona uma reflexão acerca das vantagens e contribuições que o jogo de xadrez pode exercer na aprendizagem de Geografia na educação básica. Acerca desse instrumental pedagógico, Vygotsky (1989 p. 184) assevera que “[...] embora no jogo de xadrez não haja uma substituição direta das relações da vida real, ele é, sem dúvida, um tipo de situação imaginária".

As contribuições que a prática do jogo de xadrez, enquanto um esporte intelectual insere entre os seus praticantes compõem-se de um leque ampliado de benefícios, uma vez que exige por parte dos enxadristas uma concentração, raciocínio e análise extremamente complexa, cabendo aos professores explorar tais mobilizações para potencializar o desempenho dos alunos em sala de aula. 
Assim como qualquer outro jogo, o xadrez também permite um acentuado espírito competitivo entre os seus envolvidos, favorecendo o desenvolvimento psicológico, a integração social e a organização do pensamento dos alunos. Isso ocorre pelo fato de que o xadrez simula uma situação de enfrentamento, desafios e dificuldades, sendo que a busca por solucionar essas situações se apresentam como carregadas de um significativo valor pedagógico. Cada participante atua como um general na condução de um exército, sendo que suas decisões são cruciais para vencer ou perder a batalha (lúdica), materializando em escala diminuta o que pode ocorrer em um combate de guerra. Toda essa complexidade presente no jogo de xadrez favorece (indiretamente) a aprendizagem de outros assuntos como a história, matemática, geometria, geografia, biologia, entre outras disciplinas convencionais do currículo escolar nas quais o docente seja capaz de construir vinculações didáticas juntos aos alunos. Tal situação decorre do fato de que os alunos precisam de um raciocínio ampliado e ágil a fim de que possam antever situações e jogadas de seus adversários no jogo de xadrez.

É por isso que a inserção do jogo de xadrez nas aulas representa um cuidado e busca pela inovação das práticas de ensino, pois;

O jogo como promotor da aprendizagem e do desenvolvimento, passa a ser considerado nas práticas escolares como importante aliado para o ensino, já que colocar o aluno diante de situações lúdicas como jogo pode ser uma boa estratégia para aproximá-lo dos conteúdos culturais a serem veiculados na escola. (KISHIMOTO 2002, p. 13).

Assim, através da prática do xadrez os discentes mobilizam sua capacidade de criatividade, intuição e paciência, características essas tão escassas nos jovens. Considerando essas e outras justificativas em relação aos benefícios que o xadrez pode trazer junto ao ensino de Geografia, essa pesquisa utilizou enquanto método científico a pesquisa bibliográfica, uma vez que tal procedimento permitiu uma melhor compreensão à temática proposta. Para tanto, o embasamento práticoteórico acerca do jogo de xadrez se utilizou de autores como: (ARAÚJO, 2007); 
(COBRA, 2016); (EADE, 2011); (LAUAND, 1988); (ROCHA, 2009); (SÁ, 2005, 2012, 2013) e (VYGOTSKY, 1989). Com relação à importância do xadrez no meio educacional o estudo se aportou nos seguintes autores: (ATALAIA, 2008); (FERRACINI, 1988); (KISHIMOTO, 2012) e (VERRI; ENDLICH, 20009). Já a interação do xadrez junto às concepções/categorias geográficas ocorreu com base nos autores, a saber: (FINATTI; FERRAZ, 2011); (HAESBAERT, 2000, 2004); (RAFFESTIN, 1993); (SANTOS, 2008) e (SOARES, 2014). As peculiaridades desse método permitem a abrangência e um melhor conhecimento de fontes de conhecimento, através de artigos, livros, jornais e etc. Refere-se a esforço que reúne informações e dados que servirão de embasamento para construir as investigações aqui propostas.

Conforme assevera Marconi; Lakatos (2003), o aporte bibliográfico “oferece meios para definir e resolver não somente problemas já conhecidos, como também explorar novas áreas onde os problemas não se cristalizaram suficientemente" (p. 183). Corroborando desta ideia, Boccato (2006) aponta que “[...] a pesquisa bibliográfica busca a resolução de um problema (hipótese) por meio de referenciais teóricos publicados, analisando e discutindo as várias contribuições científicas" (p. 266). Os argumentos aqui levantados são resultantes da necessidade e coerência que uma abordagem didático-pedagógica complexa exige, sendo que o jogo de xadrez tem a capacidade de contribuir de forma significativa com esse propósito. Com isso, evidencia-se a importância do jogar e brincar, em que a criança irá "modelar" o mundo em seu entorno, uma construção social na “[...] qual a imaginação, a fantasia e a realidade interagem na produção de novas possibilidades, de interpretação, de expressão e de ação pelas crianças, e assim como de novas formas de construir relações sociais com outros sujeitos" (VYGOSTKY, 1989, p. 35).

Segundo Grassi (2008, p. 124) durante o processo de jogar:

Os participantes são incentivados a jogar bem e a se aperfeiçoar; as funções mentais superiores são colocas em movimento, são estimuladas, exercitadas desenvolvem - se e se aperfeiçoam na busca por melhores resultados; disciplina, a concentração, a perseverança e a flexibilidade 
são valorizadas; aperfeiçoam-se esquemas de ação, criam - se e se descobrem estratégias mais eficientes para o jogo.

A utilização do xadrez pedagógico oportuniza que sejam trabalhados diversas composições e valores éticos e morais junto aos educandos, a exemplo da noção do "saber ganhar e perder" nas relações sociais, além da sujeição as imposições e regramentos que estão presentes em qualquer jogo. Um trabalho realizado de forma contínua e coerente com o desenvolvimento cognitivo de cada faixa etária dos estudantes permite que esses percebam a sua própria desenvoltura cognitiva, uma vez que é dado espaço para o aluno expor o seu processo cognitivo-construtivo, e perceber os raciocínios que emprega no desenrola do jogo, sendo que a cada resultado negativo (ou positivo) surgem novas interpretações Ihe são assimiladas/acomodadas. Portanto, a prática do xadrez é uma ferramenta didática que pode ser utilizado em momentos distintos, complementando a aula teórica, tornando-a mais atrativa, motivadora e dotada de significados para os alunos.

\section{LÓGICAS DA APLICABILIDADE DO JOGO DE XADREZ JUNTO AO MEIO EDUCACIONAL}

É importante deixar bem esclarecido que as tratativas aqui dialogadas não possuem o propósito de reduzir o processo de ensino-aprendizagem ao espírito competitivo dos jogos $^{1}$. O que se pretendeu foi evidenciar a importância que o brincar e o jogar carrega como aporte em construir nos alunos um raciocínio lógico que seja ancorado em estratégias/concepções críticas, de concentração, interação e criatividade. Para Grassi (2008, p. 98) “jogar se caracteriza pelo prazer e pelo

\footnotetext{
${ }^{1}$ Não defendemos o jogo pelo jogo, pois parece uma situação pouco estruturada e sem perspectivas relevantes quanto ao processo de desenvolvimento dos indivíduos. Estamos pensando no seu uso como recurso pedagógico, pois no jogar o aluno articula tanto a teoria quanto a prática, fazendo com que ele estude sem perceber tornando o processo de ensino-aprendizagem mais interessante e atrativo (VERRY; ENDLICH, 2009, p. 67).
} 
esforço espontâneo. O jogo prende a atenção do jogador, cria uma atmosfera de tensão, desafio, entusiasmo, alegria e prazer". Destarte, o jogo transforma-se em uma atividade estimulante e excitante, a qual demanda dos envolvidos esforço físico e mental, o que contribuiu para uma significativa aprendizagem estudantil. Com relação à aplicabilidade do xadrez no meio educacional, são bastante significativos os benefícios que pode favorecer em relação às habilidades cognitivas em educação formal e não formal. Contudo, vale destacar que tal realização exige a tutoria de um profissional docente devidamente capacidade e que, antes de tudo, tenha entusiasmo e conhecimento pelo jogo de xadrez e também paixão pelo ato de ensinar.

É comum no meio popular atribuir aos homens que fazem o uso de cachimbo trazer consigo uma sensação de sabedoria proeminente. Da mesma forma, duas pessoas envolvidas em um jogo de xadrez representam em um primeiro momento a impressão de que são indivíduos excêntricos, enfermiços e pouco sociáveis. Essa 'mística da inteligência' cresceu em torno do xadrez em parte porque, historicamente, apenas as classes dominantes tinham tempo livre suficiente para jogar (EADE, 2011, p. 12-13). Diante disso, quando se transfere a prática do jogo de xadrez para o meio escolar, significa que se está popularizando uma prática historicamente limitada à elite cultural da sociedade. No entanto, não é esse o propósito de tal iniciativa, mas estimular o uso desse instrumento pedagógico que pode ser usado de forma lúdica e alinhado aos ritmos e tempos de cada criança, preocupação essa de vital importância no ensino moderno. Em verdade, o xadrez acaba se constituindo enquanto "[...] um dos recursos pedagógicos com mais qualidade em uma só atividade, pois incrementa várias potencialidades intelectuais, tais como: a imaginação, a atenção, a concentração, o espírito de investigação, a criatividade e a memória" (SÁ, 2005, p. 03).

Quanto ao surgimento do jogo de xadrez, Fischer (1991) pontua que sua origem história é bastante controversa, sendo que sua invenção deu-se há aproximadamente 1500 anos na Ásia. A versão mais aceita é a do seu aparecimento 
na Índia com o nome de "Chaturanga", um "antigo jogo hindu, geralmente considerado o antepassado de nosso jogo de xadrez moderno" (HORTON, 1973, p. 59). Posteriormente, esse jogo começa a se espalhar para a China, Rússia, Pérsia e Europa, onde se convencionou as regras atuais². A chegada do xadrez na Europa aconteceu por intermédio dos árabes, no século IX, sendo que além desse jogo, levaram também outros saberes científicos, no âmbito da matemática e na esfera da literatura clássica. Para Lauand (1988, p. 21-22);

Como sempre, os grandes impulsos culturais na Idade Média começam pelas traduções: o século XII, de autêntico renascimento, é um século de traduções. Por meio delas, o Ocidente recebe de volta dos árabes, com juros, a Matemática, a Filosofia, a Medicina e outras ciências. [...] E o xadrez será parte dessa influência árabe na Península [...]

No mundo ocidental o xadrez ganha um patamar de prestígio e se fazia presente junto aos círculos sociais das castas sociais mais abastadas na idade média, sendo chamado de jogo dos reis e rei dos jogos. Tamanha importância vai resultar em disputas entre os seus praticantes, sendo que em 1851 tem-se a realização do primeiro torneio internacional de xadrez, já com as regras muito próximas as convenções modernas, sendo disputado em Londres (Inglaterra). O evento foi organizado e sistematizado por Howard Staunton, marcando o primeiro encontro dos melhores competidores da Europa em um evento único. O alemão Adolf Anderssen saiu vencedor do torneio que contou com mais quinze enxadristas, recendo o status de melhor enxadrista do continente. Desde então, convencionouse o surgimento do "xadrez profissional" dada à realização de inúmeras competições ocorridas nas principais cidades europeias (SÁ, 2005).

\footnotetext{
${ }^{2} \mathrm{Na}$ Idade Média, o xadrez foi alterado de tal modo que ficou sendo uma representação da sociedade medieval, como o casal monárquico, a cavalaria, os bispos e os peões. Do século VI ao XII, na Idade Média, o equipamento usado na prática do xadrez era uma representação dos elementos básicos do exército e a função simbólica desse jogo estava associada à guerra. [...] [...] As torres simbolizam o castelo, a fortaleza e, mais especificamente, o poderio militar (ROCHA, 2009, p. 40-41).
} 
Com relação ao órgão regulador dessa modalidade esportiva, nos primeiros anos do século XX ganha força a mobilização para se instituir uma entidade reguladora, sendo que em 20 de Julho de 1924 é criada em Paris (França) a Federação Internacional de Xadrez (FIDE). Com sua sede em Lausana (Suiça), a FIDE conecta as várias federações nacionais de xadrez e atua como órgão dirigente das competições internacionais do esporte, sendo reconhecida pelo Comitê Olímpico Internacional (COI) como a responsável pelas regras do xadrez, bem como organizar os campeonatos internacionais em níveis continentais. Atualmente, a FIDE não atual apenas com o xadrez profissional, pois também é responsável pela disseminação do xadrez escolar, fazendo deste esporte intelectual um instrumento educacional. Em nível nacional existe a Confederação Brasileira de Xadrez (CBX), instituição que tem a responsabilidade de difundir o xadrez por todo o território nacional com sede em Santa Maria de Jetibá/ES, sendo criada em 06 de novembro de 1924. Atualmente possui cerca de 20 federações estaduais e diversos clubes e instituições associadas.

Diante disso, para além dessa perspectiva historicamente elitizada e profissional do xadrez, a sua utilização tem sido nos últimos tempos alinhada com o viés educativo, pedagógico e multidisciplinar. No caso brasileiro, o primeiro ato de prática efetiva do xadrez enquanto ferramenta pedagógica em instituições de ensino ocorreu nas escolas do antigo ginásio (atuais $6^{\circ}$ aos $9^{\circ}$ anos) de Jaboticabal/SP em 1935, oportunidade em que a aprendizagem de xadrez foi inserida facultativamente junto ao quadro discente. Desde então, foram aparecendo outras iniciativas nas cidades espalhadas pelo país, mas todas de formas isoladas (SÁ et al., 2012). Vale frisar que o xadrez não constitui uma obrigatoriedade integrante do currículo na educação básica, contudo, a sua utilização tem sido prática costumeira no meio escolar, sendo inicializado quase sempre como entretenimento lúdico e, aos poucos, vai ganhando contornos de instrumental pedagógico com benefícios múltiplos ao desenvolvimento cognitivo dos alunos envolvidos. 
É inegável o reconhecimento apregoado por diversos profissionais envolvidos com a educação acerca das vantagens advindas pela prática do jogo de xadrez na educação básica, sendo comum estar expressa nas publicações dessa temática indicativa como a melhoria da concentração, raciocínio lógico, imaginação, criatividade, entre outras habilidades proporcionadas ao praticante de xadrez. Afinal, o xadrez possibilita diversas variações de jogadas, que não podem ser repetidas em qualquer outro jogo de tabuleiro. O maior mérito da prática e aprendizagem enxadrística no cotidiano educacional se posiciona, segundo Sá; Rezende Júnior; Melo (2013, p. 271), no fato possibilitar que os alunos a sua maneira própria consigam uma progressão que segue o "[...] seu próprio ritmo e limite. O xadrez é capaz de funcionar como um suporte pedagógico para que os alunos alcancem a autoestima essencial em qualquer processo educativo, inclusive nos ambientes pedagógicos de baixo rendimento escolar".

De acordo com Sá et al. (2012), as investigações teóricas que discorrem em relação a inserção do jogo de xadrez na esfera educacional divide-se em duas principais orientações;

A Pedagogia do Xadrez, na qual o estudo e a prática deste esporte são considerados como formadores para o desenvolvimento global do estudante, constituindo-se como matéria curricular; A Pedagogia pelo Xadrez, segundo a qual ele representa um suporte pedagógico para outras disciplinas escolares (SÁ et al., 2012, p. 181).

As discussões aqui empreendidas buscaram evidenciar essas duas tendências, um esforço que para além da visão fragmentada das disciplinas isoladas, voltando-se em indicar a importância que o xadrez possui para formação de aspectos mais gerais do processo de ensino-aprendizagem, sendo esse associado à resolução/reflexão de problemas do cotidiano discente. Assim, análises de enfoques matemáticos, geográficos, históricos, políticos, sociais, ambientais, linguagens, econômicos, entre outros, são mobilizados de forma articulada com a realidade em questão, o que contribui para que se desenvolvam 
competências e habilidades do pensar com abrangência e profundidade. Portanto, inserir o xadrez em sala de aula de forma contextualiza trata-se de uma intervenção lúdica que auxilia a desenvolver a sensação de autoconfiança, visto que expressa "uma situação na qual o aluno tem a oportunidade de descobrir uma atividade em que pode se destacar e, paralelamente, progredir em outras disciplinas acadêmicas" (ARAÚJO, 2007, p. 07).

Dessa feita, percebe-se que o xadrez é muito mais que um simples jogo de caráter lúdico, pois se refere a um esforço recreativo que favorece o aprimoramento da capacidade de cognição dos estudantes, uma vez que exige muito o uso do raciocínio lógico no decorrer das partidas. Essa peculiaridade devese ao fato de que os jogadores precisam estar atentos a todos os movimentos e possibilidades do jogo, fazendo com que os envolvidos estejam continuamente pensando e projetando sua próxima decisão no tabuleiro, um arsenal de estratégias que busca sempre atingir seu intento dentro do jogo. Assim, basta que os envolvidos tenham um nível de compreensão relativamente significativo dessa modalidade esportiva para que o grau de tensão eleve-se exponencialmente, resultando em grandes desgastes físicos e mentais. Portanto, o xadrez não exige e fortalece apenas o aspecto mental dos seus praticantes, mas também os atributos físicos.

Acerca dessa tratativa Cobra (2016) afirma que:

É justamente por exigir tanto da mente, das emoções e dos sentidos é que se torna necessária uma grande eficiência cardiovascular para se ter uma boa performance. Quanto mais alto o nível da competição, mais clara se torna essa relação. Uma bomba ejetora mais plena (o coração) colocará nas células do cérebro uma quantidade maior de oxigênio. Esse cérebro mais oxigenado possibilitará maior eficiência, maior lucidez e, principalmente, maior velocidade do pensamento, de interpretação e reação aos movimentos complexos presentes no xadrez.

Tal cuidado é importante pelo fato de costumeiramente serem realizados campeonatos escolares em que a modalidade de xadrez está presente. Diante disso, acaba se fazendo necessário um cuidado/preparo extra para além das 
instruções efetivadas no uso rotineiro do xadrez em sala de aula (xadrez lúdico e pedagógico) sem o propósito de serem partidas eminentemente competitivas. Contudo, mesmo em aplicações convencionais da xadrez nas aulas, é ingênuo pensar que o espírito competitivo entre os alunos não se farão presentes, lógico que com bem menor intensidade em comparação ao ambiente que permeia um campeonato escolar de xadrez. Assim como qualquer outro jogo, o xadrez estimula os educandos a ficarem mais motivados a usarem "[...] a inteligência, pois querem jogar bem; sendo assim, esforçam-se para superar obstáculos, tanto cognitivo, quanto afetivo. Estando mais motivadas durante o jogo, ficam mais ativas mentalmente" (GRASSI, 2008, p. 96).

Na verdade, o xadrez se apresenta enquanto uma realização pedagógica “[...] em que dialética e autocrítica ocupam um lugar primordial e, o vencido, se enriquece e tira mais proveito que o vencedor" (ATALAIA, 2008, p. 04). O fato de demandar uma percepção muito abstrata do jogo, pois as jogadas são imaginadas antes mesmo de serem realizadas, faz com que os alunos adquiram o hábito de refletir (em curto espaço de tempo) sempre antes de movimentar cada peça, em um procedimento de antecipação. Tal prática passa também a fazer parte do cotidiano desses sujeitos, os quais passam a pensar melhor seus encaminhamentos ao realizarem tarefas dos estudos e até mesmos nas decisões da sua interação social. Essa construção da autonomia nos alunos confere-lhe um caráter pró-ativo, o qual passa a ser mais capaz de enfrentar com mais propriedade seus desafios, no interior e exterior ao ambiente escolar, além de construir/consolidar um senso de criticidade quanto ao mundo que o envolve.

Diante disso, o educando constrói a sua identidade própria, uma vez que vai aos poucos se libertando dos automatismos, isto é, os reflexos automáticos dão espaço para o aprendido, pois o sujeito passa a expressar de forma mais consolidada suas identificações inteligentes, além de fortalecer em si o sentimento de autoconfiança de forma cooperativa e solidária. Afinal, a atividade enxadrística 
se coloca na escola muito além de uma mera diversão (passatempo), pois está estruturada em uma formatação que auxilia na aprendizagem, em disciplinar o trabalho do aluno e também em incutir-Ihe comportamentos básicos necessários para formar a sua personalidade. Assim posto, esse jogo evidencia uma lógica de elevada subjetividade, válido tanto para estruturar a personalidade humana quanto a lógica formal das estruturas cognitivas.

\section{O JOGO DE XADREZ: DO TABULEIRO PARA O ENSINO DA GEOGRAFIA}

A proximidade do jogo de xadrez com a ciência geográfica decorre do fato de que ambos (em suas respectivas dimensões) possuem uma vinculação direta com as relações socioespaciais, sendo que o movimentar das peças no xadrez objetiva conquistar recortes espaciais do seu oponente. Diante disso, o jogo de xadrez se apresenta enquanto uma possibilidade instigante e facilitadora para tratar de inúmeras questões atinentes ao ensino de geografia. Trata-se de uma ferramenta que melhora a própria relação professor-aluno e aluno-aluno, isto quando as ações lúdicas presentes no xadrez são corretamente contextualizadas junto às discussões geográficas. A atividade enxadrística enquanto ferramenta pedagógica nas escolas favorece uma aprendizagem dialógica e empática, a qual impulsiona as "[...] competências e habilidades de forma interativa, envolvente, autônoma, com participação qualitativa dos sujeitos da comunidade escolar" (SILVA, 2008, p. 20). Portanto, potencializar a aprendizagem por intermédio do xadrez exige uma adequada orientação e condução pelo professor (a), devido à necessidade de o jogo estar inserido na ação docente enquanto instrumental pedagógico e não como simples passatempo.

O caráter geográfico presente no xadrez tem uma representatividade bastante aflorada, concepção essa que compreende o próprio entendimento de coordenadas geográficas quando se explica da disposição das peças e suas jogadas. 
Isso acontece pelo fato de que as laterais do tabuleiro são indicadas com letras e números, tornando possível apontar a disposição de todas as casas do jogo, raciocínio esse que é muito similar quando se discute em sala de aula a coordenada geográfica, estudo esse que exige o entendimento de latitude e longitude, entre outras aplicabilidades que estejam atreladas a compreensão do mapa mundi. Portanto, fica mais interessante conversar com um aluno praticante de xadrez sobre os sentidos de localização no plano terrestre, deixando assim a cartografia mais inteligível e fácil de ser explicada. Esse zelo pedagógico explica que a eficácia do processo ensino-aprendizagem carece de um esforço que se referencie a “[...] partir da consciência da época em que vivemos, sabendo o que o mundo é e como ele se define e funciona. É somente assim que se podem formar cidadãos conscientes e capazes de atuar no presente, ajudando a construir o futuro" (SANTOS, 2008, p. 115).

Ao fazer uso do jogo enquanto processo didático-pedagógico da educação o docente transporta "[...] para o campo do ensino-aprendizagem condições para maximizar a construção do conhecimento, introduzindo as propriedades do lúdico, do prazer, da capacidade de iniciação e ação ativa e motivadora" (KISHIMOTO, 2002, p. 37). Tendo em vista o ensino da geografia, percebe-se que uma adequada apreciação das regras do xadrez permite apontar relações com os conceitos da Geografia, a exemplo dos sentidos atribuídos a categoria do espaço, que carregam significações complexas no tabuleiro e no interior da ciência geográfica. Podem-se indicar também analogias que expliquem as concepções de território e territorialidade, conceitos esses caro aos estudos geográficos, ao explicitar a posição, o poder, as possibilidades e comportamentos que cada peça exerce no tabuleiro, assumindo funções complexas e ate mesmo diferenciadas no decorrer de uma partida de xadrez. Tais conotações são amplamente estudas junto às disciplinas de geografia política e geopolítica, uma vez que as relações de poder são evidenciadas de forma clara e objetiva. 
O entendimento mais abrangente do xadrez no meio popular remete ao confronto de dois reinos em que os oponentes visam ganhar a partida pela captura do rei adversário, isto é, uma guerra que se materializa com as suas mais diversificadas estratégias no interior de um tabuleiro com 64 (sessenta e quatro) casas. É praticamente impossível não remeter tamanha concepção com o principal conceito da geografia - o espaço, dada a diversas possibilidades de jogadas que se fazem presentes em uma simples partida de xadrez. O "lugar" de conforto, proteção e vida do rei são constantemente vigiados, juntamente com as "regiões" do tabuleiro em que se posicionam as peças mais fortes do reino oposto, além das "paisagens" se arremetem a cada rodada, o que a torna interessante ou calamitosa na perspectiva do jogo em si. Concomitante a isso tudo, o jogo exige um contínuo processo de territorialização (território) e reterritorialização dos limites do tabuleiro. Tais análises são muito exploradas quando se estuda, por exemplo, os cenários da Guerra Fria, um confronto geopolítico em que os EUA combatiam o florescimento do comunismo no continente americano e a URSS criavam um cordão de isolamento ao capitalismo no território soviético.

São múltiplas as possibilidades de materializar uma aprendizagem de geografia nos alunos com a utilização do xadrez. Para Ferracini (1998, p. 23), no jogo de xadrez é perfeitamente possível perceber uma representação da "sociedade humana em suas contradições. Nele, os poderosos podem ser destituídos, eliminados; e os plebeus (peões) podem ascender socialmente até a nobreza, é um jogo da vida real". A interpretação do entendimento de território alinhada com o xadrez discorrida por Soares; Soares (2014, p. 33) é muito interessante;

A categoria território justaposta nas regras do xadrez apresenta-se como uma aprendizagem significativa, pois no jogo é claramente demonstrado que em cada casa pode haver apenas uma peça e, se um jogador deseja se apoderar de uma casa ocupada pelo adversário, poderá tomar a peça que ali estiver tirando-a do tabuleiro e colocando sua peça no lugar, o que remonta, também, à aprendizagem da categoria geográfica lugar. 
Entretanto, "[...] saber utilizar essa potencialidade requer sensibilidade, criatividade e, principalmente, preparação didático-pedagógica, visando resultados positivos" (SILVA, 2008, p. 31). Isso diz respeito a uma iniciativa interdisciplinar, a qual ocorre por um efetivo planejamento e adaptação do jogo 3 a realidade das temáticas curriculares discorridas em sala de aula, esforço esse que estimula os alunos a compreenderem o mundo, com destaque para as construções sociais presentes em suas respectivas cotidianidades. Essa abordagem é mais bem compreendida quando os alunos entendem a função e o poder que cada peça possui no tabuleiro, sendo realizadas analogias de cada componente do jogo com pessoas, situações e/ou instituições do meio social. É aqui oportunizado um amplo leque de vínculos sobre a "divisão social do trabalho", debatida na geografia econômica e da população.

As interpretações geralmente colocam os peões como a classe trabalhadora da sociedade, as torres como a propriedade privada, os cavalos como a guarda, os bispos como clero e o rei e rainha como a elite desse mundo próprio que é o jogo de xadrez. A figura 1 representa de forma bem explícita esse arranjo, a qual se trata de uma representação instruída em "[...] uma figuração de base monárquica, com seus constituintes principais: a nobreza, o clero, os militares, o povo" (FINATTI; FERRAZ, 2011, p. 72). Vale frisar que não necessariamente deve ser essa a analogia adotada, cabendo a cada docente adaptar da forma mais didática possível a incursão dessas reflexões em sala de aula. Contudo, várias funcionalidades do Estado são facilmente compreendidas pelos alunos tendo por base a disposição das peças no tabuleiro de xadrez, uma vez que "[...] três sinais são mobilizados para caracterizar o Estado: a população, o território e a autoridade. Toda a

\footnotetext{
${ }^{3}$ No xadrez, de acordo com sua importância para a batalha, as peças possuem um determinado poder, entendido aqui como o poder de captura diretamente relacionado à sua abrangência territorial. Com isso, interagem com as demais peças em um sistema territorial complexo e essa informação é repassada ao jogador adversário, que a cada lance da partida faz uma releitura, não apenas do último lance em si, mas de todas as consequências do último lance para o conjunto das peças no tabuleiro (FINATTI; FERRAZ, 2011, p. 83).
} 
geografia do Estado deriva dessa tríade" (RAFFESTIN, 1993, p. 23). A conotação de território é possível de ser trabalhada em várias frentes, podendo ser compreendido como o tabuleiro em sua integridade em que se dá a batalha lúdica ou os limites iniciais de cada lado oposto do jogo, sendo percebido um território das peças brancas e frontal ao das peças pretas.

Figura 1 - Disposição inicial das peças no tabuleiro de xadrez.

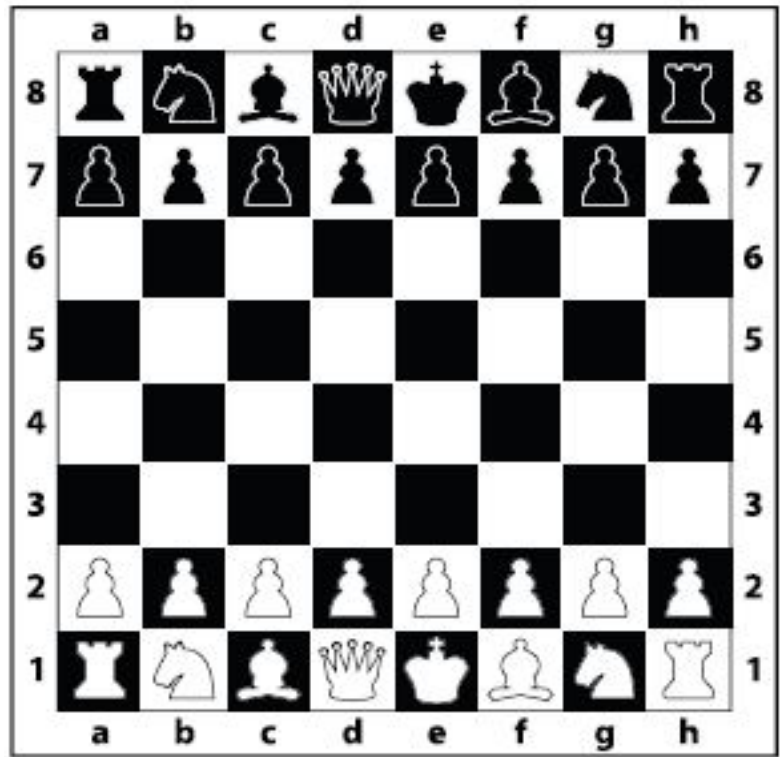

Fonte: Acervo particular do autor (setembro de 2020)

No tabuleiro de xadrez é possível interpretar também a existência de uma multiterritorialidade (isto é, uma dinâmica combinada de múltiplas territorialidades e territórios) conforme assevera Haesbaert (2004). No início do jogo se faz presente uma configuração clássica de dois territórios-zona conforme evidencia a figura 1, pois as peças estão combinadas em faixas zonais cada qual em extremidades opostas do tabuleiro. Na reflexão geográfica os territórios-zona compreendem os limites territoriais mais tradicionais, tendo com áreas e recortes relativamente bem demarcados, a exemplo do próprio Estado-Nação (HAESBAERT, 2004). Voltando ao xadrez, no decorrer da partida as peças mudam totalmente a configuração de suas posições iniciais, surgindo partes do tabuleiro que concentram mais ou menos peças, haja vista as distintas estratégias de ataque e defesa naturais do jogo. Esse quadro é bastante análogo ao entendimento dos 
territórios-rede na geografia, que “[...] são por definição, sempre, territórios múltiplos, na medida em que podem conjugar territórios-zona (manifestados numa escala espacialmente mais restrita) através de redes de conexão (numa escala mais ampla) (HAESBAERT, 2004, p. 40).

Por fim, quando a partida vai chegando ao seu término, pode-se fazer uma analogia com os chamados aglomerados de exclusão que integram o sentido de multiterritorialidade, os quais figuram uma mesclagem confusa de territórios-zona e territórios-rede, os territórios passam a serem desprovidos de uma cartografia espacialmente bem delimitada. Por representarem os grupos sociais segregados, inseguros e instáveis territorialmente, os quais já não exercem um efetivo controle sobre seus territórios (HAESBAERT, 2004), fica fácil visualizar no cenário final de uma partida de xadrez em que grande parte das peças já foram capturadas que poucas que restam são insuficientes para manter um nível significativo de ataque/defesa no jogo. Aqui é possível inserir também outra reflexão geográfica envolvendo os sentidos do território, ou seja, a sua compreensão sob a perspectiva do uso discorrida em Santos (2005). Assim, ciente de que o território só ganha significação quando é considerado na perspectiva do seu uso, igualmente no jogo de xadrez a efetiva territorialização do tabuleiro só acontece com um posicionamento estratégico das peças de forma que se consiga controlar/proteger o maior número de casas possíveis no jogo, bem como estabelecer-se em quadrantes que efetivamente tenha influencia positiva no jogo.

Dessa feita, a atividade enxadrística se coloca como uma importante ferramenta pedagógica junto ao ensino de geografia, realização essa que tem a capacidade de tornar as aulas mais atrativas e participativas para os alunos, considerando que os discentes percebem de maneira mais efetiva exemplos e utilidades dos conceitos geográficos. A utilidade do xadrez, conforme exposto nesse estudo, consegue atender os diferentes níveis de escolaridade da educação, sendo que no caso da geografia da conta de sistematizar tanto aos conteúdos 
escolares mais elementares que se relacionam a localização e posicionamento no espaço, mas também as teorizações de maior complexidade, como a compreensão do conceito de território. Afinal, a educação só faz sentido quando o educando de fato é colocado em posição de protagonismo nesse processo, fomentando assim que a escola possa cumprir a sua função social e formar um sujeito social e cultural dotado de criticidade que possa viver e conviver bem em sociedade. Portanto, o jogo de xadrez pode ser um aliado do professor, instrumental esse que será fundamental para dinamizar as discussões prático-teóricas discutidas em sala de aula.

\section{CONSIDERAÇÕES FINAIS}

Os levantamentos inquiridos ao longo dessa pesquisa permitem afirmar que a inserção do xadrez enquanto prática pedagógica (discursiva e dialógica) é uma realização social capaz de provocar mudanças muito proveitosas no desempenho escolar dos estudantes, pois a internalização dos preceitos desse jogo junto aos educandos institui-Ihe uma formação dinâmica, ativa e singular que os condiciona a atuar proativamente no mundo a sua volta. Tal constatação pode ser aferida pela compreensão das principais categorias geográficas que se fazem presentes em uma partida de xadrez, exercício intelectual esse que consegue de maneira prazerosa incutir nos jogadores a noção de espaço geográfico, território, lugar, região, poder, entre outras apreensões que delineia a geografia escolar. Essa amplitude de concepções que abarca diretamente o vivido desses sujeitos acaba por condicioná-los não apenas a compreender, mas também agir sobre as relações espaciais, nas mais diversas ocorrências e invenções das práticas e atividades humanas.

Diante do exposto, fica claro que as possibilidades de intervenção pedagógica presente no jogo de xadrez apresentam um potencial extremamente produtivo que otimiza a aprendizagem, uma realidade que traz uma carga 
interdisciplinar muito acentuada e, portanto, não apenas os estudos geográficos, mas todas as demais disciplinas podem igualmente fazerem uso a fim de melhorar o desempenho estudantil de seus alunos. Além disso, a prática do xadrez é um exercício que pode contribuir com diversas outras implicações educativas e sociais dos sujeitos envolvidos. Isso ocorre em virtude de que em todo jogo de xadrez temse a mobilização do pensamento crítico, mesmo nos embates travados entre jogadores fracos que pouco conhecem as regras de movimento das peças. Por isso tudo, é legítimo ratificar a validade que os construtos pedagógicos presentes no jogo de xadrez carecem de serem compreendidos como um importante estágio de assimilação/acomodação de conhecimentos/saberes e, como tal, o seu estímulo e continuidade precisam ser valorizados pela comunidade escolar, pela estrutura curricular e pelos profissionais da educação.

Conforme já anunciado ao longo do presente ensaio, é interessante lembrar que as abordagens didáticas do xadrez escolar não devem ser realizadas enquanto uma "prática pela prática", a qual o interpreta apenas como um jogo pelo jogo. A sua produtividade e virtude necessita de que seja compreendida para além das suas configurações técnicas, uma iniciativa que seja devidamente assistida por profissionais cientes das múltiplas dimensões e potencialidades pedagógicas do jogo de xadrez, uma iniciativa no qual estes se posicionem enquanto vetores da produção de cultura, e não tão somente de sua reprodução. Isto é, faz-se necessário que o docente faça a mediação entre o ensino e significado do conceito e a situação ocorrida no decorrer das partidas, além de atentar-se para o nível de ensinamentos desse jogo condizente com cada faixa etária. A inserção do xadrez enquanto tarefa de desenvolvimento cognitivo é uma prática que pode ser estimulada a partir dos 3 (três) anos de idade da criança, um exercício intelectual que é recomendado de forma benéfica até o instante em que a pessoa ainda tenha um raciocínio lógico sobre o jogo. 
Por fim, cabe discorrer acerca do baixíssimo custo operacional que é a inclusão do xadrez nas escolas quando comparado a outros tipos de investimentos pedagógicos. Esse esporte dispensa a construção de estádios, campos, quadras, piscinas, entre outros aportes infraestruturais específicos, pois é possível de ser realizado na própria sala de aula. Com relação aos tabuleiros e peças, esses são de durabilidade muito ampliada, cabendo apenas que professores e alunos se atentem para evitar extravios, percas e avarias nesses objetos. Assim, quando se observa a relação investimento-retorno, o xadrez se mostra como umas das melhores opções para fomentar o desenvolvimento integral do ser humano, uma realização que ao ser integrado no meio escolar, esteja pautada em uma educação de valores humanizados, por intermédio da vivência, reflexão e práxis inovadora desenvolvida.

\section{REFERÊNCIAS}

ARAÚJO, A. A. O xadrez como atividade lúdica na escola: uma possibilidade de utilização do jogo como instrumento no processo ensino-aprendizagem. In: IV Semana Acadêmica da FSBA, 2006. Centro Universitário do Instituto Social da Bahia, Salvador/BA, 2007. Disponível em: http://www.fsba.edu.br/semanaacademica2006/TEXTOS/ANDRE\%20 DE\%20ALMEI DA\%20ARAUJO.pdf. Acesso em: 24 out. 2020.

ATALAIA, M. F. C. Xadrez e Educação. Jornal Cidade de Tomar, Tomar. Artigos publicados ao longo do ano de 2008.2 Disponível em: http://paulojlcosta.weebly.com/uploads/1/6/7/1/1671352/artigos_de_manuel_atalaia.pdf. Acesso em: 20 out. 2020.

BAUMAN, Z. Tempos líquidos. Tradução Carlos Alberto Medeiros. Rio de Janeiro: Jorge Zahar, 2007.

BERGAMO, M. O uso de metodologias diferenciadas em sala de aula: uma experiência no ensino Superior. Revista Eletrônica Interdisciplinar, Vale do Araguaia, v. 2, n. 4. 2010.

BOCCATO, V. R. C. Metodologia da pesquisa bibliográfica na área odontológica e o artigo científico como forma de comunicação. Rev. Odontol. Univ. Cidade São Paulo, São Paulo, v. 18, n. 3, p. 265-274, 2006. 
COBRA, N. Jogar Xadrez Exige Preparo Físico: O xadrez é um esporte muito amplo. Blog Vya Estelar, 2016. Disponível em: https://www.vyaestelar.com.br/post/6112/jogar-xadrez-exigepreparo-fisico. Acesso em: 21 out. 2020.

EADE, J. Xadrez: o guia definitivo. Tradução LEAL, Marcos Malvezzi. São Paulo: Marco Zero, 2011.

FERRANCINI, L. G. Xadrez no currículo escolar ensinando xadrez para crianças a partir de 3 anos. $1^{\circ}$ edição. Londrina/PR: Editora Midiograf, 1998.

FINATTI, R.; FERRAZ, C. B. O. Linguagem geográfica do jogo de xadrez: uma aproximação ao conceito de território e ao processo de ensino-aprendizagem. In: NUNES, F. G. (Org.). Ensino de geografia: novos olhares e práticas. Dourados, MS: UFGD, 2011. p. 61-99.

FISCHER, J. Como é fácil aprender xadrez. Porto Alegre: Editora Rígel, 1991.

GRASSI, T. M. Oficinas Psicopedagógicas. 2 ed. Curitiba: Ibpex, 2008.

HAESBAERT, R. O mito da desterritorialização: do "fim dos territórios" à multiterritorialidade. Rio de Janeiro: Bertrand Brasil, 2004.

HAESBAERT, R. Da Desterritorialização à Multiterritorialidade. Boletim Gaúcho de Geografia, Porto Alegre, v. 29, n. 1, 2003.

HORTON, B. J. Moderno dicionário de xadrez. Tradução de Flávio de Carvalho Junior. $3^{a}$ ed. São Paulo: Ibrasa, 1973.

KISHIMOTO. T. M. Jogo, brinquedo, brincadeira e a educação. São Paulo: Cortez, 2002.

LAUAND, L. J. O xadrez na Idade Média. São Paulo, 1988.

MARCONI, M. A.; LAKATOS, E. M. Fundamentos de metodologia científica. $5^{a}$. ed. São Paulo: Atlas, 2003.

RAFFESTIN, C. Por uma geografia do poder. São Paulo: Atica, 1993.

ROCHA. W. R. Jogo e o Xadrez: Entre Teorias e a História. 2009. Dissertação. (Mestrado) Universidade Católica de Goiás, Departamento de História, Ciências Sociais e Relações Internacionais.

SÁ, A. V. M. Considerações gerais sobre a aprendizagem de xadrez no ensino. In: Brasil: Ministério do Esporte. Iniciação esportiva. Brasília: Cead/UnB, 2005. p. 151-160. v. 2.

SÁ, A. V. M.; SILVA, W.; SUNVE, J.; TONEGUTTI, C. A. Apontamentos sobre o ensino do xadrez no Brasil: o projeto nacional e o projeto do Paraná. In: SILVA, W. (Org.). Xadrez e educação: contribuições da ciência para o uso do jogo como instrumento pedagógico. Curitiba: Editora UFPR, 2012. cap. 15, p. 355-372. 
SÁ, A. V. M.; REZENDE JÚNIOR, L. N.; MELO, W. A. Benefícios lúdicos e pedagógicos do xadrez. In: SÁ, A. V. M. (Org.). Ludicidade e suas interfaces. Brasília: Liber Livro, 2013. cap. 14, p. 265281.

SANTOS, M. Espaço e método. São Paulo: Editora da USP, 2008.

SILVA, R. R. V. O Jogo de Xadrez como Recurso Didático-Padagógico nas Aulas de Educação Física. UFSC. Florianópolis/SC. Revista Motrivivência, ano XX, n³1, p. 19-35, dez./2008.

SOARES, A. P.; SOARES, S. P.; O jogo de xadrez como metodologia para o ensino de geografia. Cadernos de Pesquisa/UFMA, São Luís, p. 01-12, 20 nov. 2014.

VERRI, J. B.; ENDLICH, A. M. A utilização de jogos aplicados no ensino de Geografia. Revista Percurso - NEMO, Maringá, v. 1, n. 1, p. 65-83, 2009.

VYGOTSKY, L. S. A formação social da mente. São Paulo: Martins Fontes, 1989.

\section{1 - Émerson Dias de Oliveira:}

Doutor em Geografia pela Universidade Estadual de Londrina (UEL). Pedagogo da Secretaria Municipal de Educação, Cultura e Turismo de Laranjeiras do Sul/PR. https://orcid.org/0000-0002-0758-7663 - cooperativismopopular@hotmail.com Contribuição: Montagem e coleta de dados; Tabulação, análise estatística dos dados e criação de tabelas e figuras; Redação do texto e padronização das normas de acordo com a revista; Revisão do texto e adição de partes significativas.

\section{2 - Cleiton Costa Denez:}

Doutor em Geografia pela Universidade Estadual de Maringá (UEM). Professor da Secretaria de Estado de Educação do Paraná - SEED/PR.

https://orcid.org/0000-0002-4344-3077 - cleiton.denez@hotmail.com

Contribuição: Redação do texto e padronização das normas de acordo com a revista; Revisão do texto e adição de partes significativas.

\section{3 - Josiane Mendes Peschisky:}

Pedagoga pela Universidade Estadual do Centro-Oeste (UNICENTRO). Especialista em Gestão Escolar pela UNICENTRO. Professora da Secretaria Municipal de Educação, Cultura e Turismo de Laranjeiras do Sul/PR.

josipeschisky@hotmail.com

Contribuição: Revisão do texto e adição de partes significativas.

\section{Como citar este artigo}

DE OLIVEIRA, E. D.; DENEZ, C. C.; PESCHISKY, J. M. O uso do xadrez enquanto realização lúdica que favorece a aprendizagem e ensino de geografia na educação básica. Geografia Ensino \& 
24 | O uso do xadrez enquanto realização lúdica que favorece a aprendizagem e ensino de geografia na educação básica

Pesquisa, Santa Maria, v. 25, e29, p. 1-24, 2021. DOI 10.5902/2236499455326. Disponível em: https://doi.org/10.5902/2236499455326. Acesso em: dia mês abreviado. ano. 